Original Article

\title{
A Descriptive Study to Assess Compassion Fatigue and Compassion Satisfaction among Caregivers of Patients undergoing Chemotherapy in selected Hospital in a City of India
}

\author{
Ujwwala Murkute', U.jawala Veer ${ }^{2}$ \\ ${ }^{1}$ Associate Professor, ${ }^{2}$ Clinical Instructor, Sadhu Vaswani College of Nursing, Pune, Maharashtra, India. \\ DOI: https://doi.org/10.24321/2455.9318.202101
}

\section{I $\quad \begin{array}{lllll}\mathbf{N} & \mathbf{F} & \mathbf{O}\end{array}$}

\section{Corresponding Author:}

Ujjwala Murkute, Associate Professor, Sadhu Vaswani College of Nursing, Pune, Maharashtra, India.

E-mail Id:

ujjwalamurkute@gmail.com

Orcid Id:

https://orcid.org/0000-0001-7500-4792

How to cite this article:

Murkute U, Veer U. A Descriptive Study to Assess Compassion Fatigue and Compassion Satisfaction among Caregivers of Patients undergoing Chemotherapy in selected Hospital in a City of India. Int J Nurs Midwif Res. 2021;8(1):2-8.

Date of Submission: 2021-02-03

Date of Acceptance: 2021-02-20

\section{$\begin{array}{llllllll}\mathbf{A} & \mathbf{B} & \mathbf{S} & \mathbf{T} & \mathbf{R} & \mathbf{A} & \mathbf{C} & \mathbf{T}\end{array}$}

Introduction: Patients and their loved ones experience variable degrees of fear and anxiety during cancer treatment. In such times, family becomes an integral part of the patient's support system. Family members may also experience similar stress like health professionals while dealing with the patient's diagnosis and its long term treatment.

Objectives: The study was aimed at assessing the level of compassion fatigue and compassion satisfaction among family caregivers of patients undergoing chemotherapy and to seek an association of compassion fatigue with selected demographic variables.

Methods: In this exploratory descriptive study, 80 family caregivers were included with non-probability convenience sampling from the chemotherapy unit of tertiary care hospital. Data related to compassion fatigue and compassion satisfaction were collected from family caretakers of patients visiting for the chemotherapy cycles with 27 point rating scale.

Results: Mean compassion satisfaction and mean compassion fatigue was 41.16 and 52.35 respectively. Majority of caregivers 41 (51.2\%) had average satisfaction level while 39 (48.8\%) had high satisfaction level. In the case of assessment of the level of compassion fatigue, majority of participants (92.5\%) had high compassion fatigue and only (7.5\%) had moderate compassion fatigue. Monthly income was found to be significantly associated with the level of compassion satisfaction whereas relation with patients was found to be significantly associated with the level of compassion fatigue among caregivers.

Conclusion: The findings of the study suggests that the caregivers had high to moderate compassion satisfaction while taking care of their loved ones during chemotherapy.

Keywords: Compassion Fatigue, Compassion Satisfaction, Chemotherapy, Family Caregiver 


\section{Introduction}

Compassion fatigue, also known as secondary traumatic stress, is a condition characterised by a gradual lessening of compassion over time. ${ }^{1}$ In general, compassion fatigue is said to be the result of exposure to emotionally or physically distressed individuals rather than a personal experience of distress. Compassion Fatigue (CF) can be related to a variety of negative feelings and emotions. These emotions may include anger, irritability, exhaustion and poor coping behaviour. Sometimes it may increase the risk of substance abuse, inability to care for someone, lack of interest in enjoyment or other activities. It may also lead to a negative effect on work related satisfaction, attendance at workplace, ability to make decisions and care for significant others in their life. ${ }^{1}$

The term 'compassion fatigue' is predominantly used with professional caregivers, such as nurses, doctors and social workers, but it can be seen among anyone who works directly with trauma victims or constantly deals with people who are in a state of crisis. ${ }^{2}$ Family caregivers of patients suffering from chronic diseases like cancer constitute one of the vulnerable groups to develop compassion fatigue over a period of time especially due to nature of the disease, treatment duration, and longer survival of patients. ${ }^{3}$

Seeing the cancer patients going through pain and discomfort can create distress among family members. Fatigue and irritability experienced by the patient and family can cause a negative impact on the family system. ${ }^{4}$ Family caregivers may experience burnout when there is a prolonged state of distress which may lead to anger, anxiety, depression, irritability, frustration and fearfulness in the long run. Burnout tends to develop gradually over time and, though a caregiver may feel exhausted, he or she continues to feel empathy and a desire to care for their loved one. In contrast, compassion fatigue often develops suddenly, though most often after a period of burnout. A caregiver who was previously very empathic and caring may feel a lack of empathy or even indifference when it comes to caring for their loved one or patient with cancer. ${ }^{5}$

On the other hand, compassion satisfaction is a positive aspect of helping. It is a feeling of pleasure and satisfaction derived from helping people who are in need. Helping the sick and dependent gives a sense of inner satisfaction and fulfilment. Compassion fatigue and Compassion satisfaction are negatively associated. The presence of compassion fatigue may affect the individual's sense of efficacy and prevent him/her from experiencing compassion satisfaction. It is defined as the positive feeling of being able to help others with the ability to perform one's job correctly. It enables people to enjoy their work by helping others which in turn improves the quality of care and is associated with the satisfaction of patients. ${ }^{6,7}$

\section{Need of the Study}

Compassion fatigue is a well-recognised mental health issue for those who work with cancer patients. Burton $L$ et al. examined the relationships between the provision of care by family members and their health behaviours and health maintenance. It was found that family caregivers have a high chance of getting inadequate rest, inadequate time for exercise and may even forget to take their own prescription drugs. In order to be able to give care persistently to someone who is chronically ill, caregivers should be given frequent relief from such work to reduce their stress. ${ }^{8}$ Patients always remain central to health care services and caregivers get very little help from health care professionals in managing their tasks and the emotional demands of caregiving. ${ }^{9}$ Even though the importance of caregivers in a patient's recovery is well recognised, health professionals invariably fail to give attention to caregivers and their potential problems. Caregivers who are employed may find it difficult to perform employment obligations along with the role of a caregiver. This may affect their financial and professional aspect of life. ${ }^{10}$

Family caregivers, thus have a huge responsibility of patient home management which may result in mental and physical stress. Issues discussed in the area of psychological health of caregivers include anxiety, worry, burden, depression, and anger. The vital role, which these family members play as "caregivers", is well recognised; however, the burden on them is poorly understood. ${ }^{11}$ Therefore the current study was taken up to assess the level of compassion fatigue and compassion satisfaction among family caregivers of patients undergoing chemotherapy and to seek the association of compassion fatigue with selected demographic variables.

\section{Methods}

80 family caregivers who accompanied cancer patients to the chemotherapy unit of tertiary care hospital from Pune, Maharashtra were selected in this exploratory study. Primary family caregivers who were literate, 18 years and above and caregivers of patients having completed a minimum of 3 cycles of chemotherapy were invited to participate in the study. Data were collected using a structured questionnaire to assess demographic variables. A rating scale was used to measure the level of compassion fatigue. Section $A$ of the tool assessed demographic data of caregivers of patients undergoing chemotherapy. It contained a total of 6 items: age, sex, education, monthly income, relation with patient and period of caregiving. Section B was a rating scale to assess compassion fatigue. It consisted of a total of 27 items, out of which 13 items were for assessing compassion satisfaction and 14 items were for assessing compassion fatigue. Each item had five opinions viz. never, rarely, sometimes, often, very often. The maximum obtained score of response for compassion satisfaction and compassion 
fatigue were 63 and 58 respectively. The validity of the rating scale was established in consultation with experts. It was validated by 11 experts in the field of nursing, oncology and statistics. To assess compassion fatigue among caregivers the score of rating scale was grouped into categories like low, average, and high according to the tertile range method. The Cronbach Alpha test was used to assess the reliability of tool. The result of the test was 0.76 which confirmed the reliability of the tool.

The study commenced after the approval of the Institutional Ethics Committee, permission from the concerned authority of the selected hospital and informed consent from the subjects. The data collection process began on 28th October 2019 and lasted till 31st Jan 2020. Each subject was explained about the study and its purpose. Subjects who agreed to join the study were given the self-structured tool.

SPSS version 17.0 for Windows developed by IBM Corporation was used in data analysis in this study. The ANOVA test and Mann-Whitney test were used to correlate compassion fatigue and compassion satisfaction with demographic variables. A probability value of 0.05 was accepted as the level of statistical significance. The level of statistical significance for this study was set at $95 \%$.

\section{Results}

\section{Section I: Family Caregivers' Demographic Data}

Majority of participants were in the age group of 40-49 years $(37.5 \%)$ and $30-39$ years (32.5\%). Majority of the caregivers 42 (52.5\%) were males. 34 (42.5\%) participants had higher secondary education and 27 (33.8\%) were graduates. $50(62.5 \%)$ caregivers were salaried, with 31 (38.8\%) participants having monthly income between INR 15000-50,000.

Majority (42.5\%) of caregivers had been providing care for 6 months and most of them were either spouse (36.3\%) or children $(30 \%)$ of patients. As per the diagnosis of participants, lung cancer (15\%), breast cancer (12.5\%), and oral cancer (12.5\%) were the most common. Rest of the participants had other types of cancer (60\%).

\section{Section II: Assessment of Compassion Satisfaction and Compassion Fatigue}

As depicted in Table 1, mean compassion satisfaction and mean compassion fatigue were 41.16 and 52.35 respectively.
Table 2 suggests that majority of caregivers (41, 51.2\%) had average satisfaction level while 39 (48.8\%) had high satisfaction level. As regards to assessment of the level of compassion fatigue, majority of participants $(74,92.5 \%)$ had high compassion fatigue and only 6 (7.5\%) had moderate compassion fatigue. None of the participants reported low compassion fatigue or compassion satisfaction.

Table I.Descriptive Statistics of Compassion Satisfaction and Compassion Fatigue

\begin{tabular}{|c|c|c|c|c|}
\hline Parameters & Mean & SD & $\begin{array}{c}\text { Minimum } \\
\text { Score }\end{array}$ & $\begin{array}{c}\text { Maximum } \\
\text { Score }\end{array}$ \\
\hline $\begin{array}{c}\text { Compassion } \\
\text { satisfaction }\end{array}$ & 41.16 & 4.987 & 29 & 58 \\
\hline $\begin{array}{c}\text { Compassion } \\
\text { fatigue }\end{array}$ & 52.35 & 6.335 & 34 & 63 \\
\hline
\end{tabular}

Table 2.Compassion Satisfaction and Compassion Fatigue

\begin{tabular}{|c|c|c|c|}
\hline \multirow{2}{*}{ Parameters } & \multicolumn{3}{|c|}{ Level - $\mathbf{n}(\%)$} \\
\cline { 2 - 4 } & Low & Average & High \\
\hline Compassion satisfaction & $0(0)$ & $41(51.2)$ & $39(48.8)$ \\
\hline Compassion fatigue & $0(0)$ & $6(7.5)$ & $74(92.5)$ \\
\hline
\end{tabular}

Section III: Association of Compassion Satisfaction and Compassion Fatigue with Selected Demographic and Clinical Variables

Table 3 shows that the P-value corresponding to monthly income, compared with the level of compassion satisfaction was less than 0.05 . Monthly income was significantly associated with the level of compassion satisfaction among family caregivers. Other demographic variables like age, gender, education, occupation and period of caregiving were not significantly associated with compassion satisfaction. Relation with patients was found to be significantly associated with compassion fatigue among caregivers. Other demographic variables like age, gender, education, occupation, marital status and period of caregiving were found to be not significantly associated with compassion fatigue. Table 4 shows that compassion fatigue and compassion satisfaction have a significant negative correlation to each other.

Table 3.Association of Compassion Satisfaction and Compassion Fatigue with their Selected Demographic and Clinical Variables

\begin{tabular}{|c|c|c|c|c|c|c|c|c|c|}
\hline \multirow{2}{*}{ Characteristics } & \multirow{3}{*}{ Frequency } & \multicolumn{3}{c|}{ Compassion Satisfaction } & \multicolumn{5}{c|}{ Compassion Fatigue } \\
\cline { 2 - 9 } & & Mean & SD & F or Z Value & P Value & Mean & SD & F or Z Value & P Value \\
\hline Age (years) & 16 & 40.75 & 5.158 & 0.05 & 0.98 & 49.75 & 7.113 & 1.79 & 0.16 \\
\hline $21-30$ & 16 &
\end{tabular}




\begin{tabular}{|c|c|c|c|c|c|c|c|c|c|}
\hline $31-40$ & 28 & 41.29 & 5.836 & \multirow{3}{*}{0.05} & \multirow{3}{*}{0.98} & 53.68 & 6.123 & \multirow{3}{*}{1.79} & \multirow{3}{*}{0.16} \\
\hline $41-50$ & 25 & 41.16 & 4.767 & & & 51.68 & 6.243 & & \\
\hline$>50$ & 11 & 41.45 & 3.110 & & & 54.27 & 5.042 & & \\
\hline \multicolumn{10}{|l|}{ Gender } \\
\hline Male & 42 & 41.98 & 4.734 & \multirow{2}{*}{0.95} & \multirow{2}{*}{0.34} & 51.14 & 6.147 & \multirow{2}{*}{1.90} & \multirow{2}{*}{0.058} \\
\hline Female & 38 & 40.26 & 5.166 & & & 53.68 & 6.351 & & \\
\hline \multicolumn{10}{|l|}{ Education } \\
\hline Illiterate & 03 & 41.67 & 3.215 & \multirow{5}{*}{1.59} & \multirow{5}{*}{0.19} & 54.33 & 3.512 & \multirow{5}{*}{0.57} & \multirow{5}{*}{0.68} \\
\hline Primary & 03 & 36.33 & 3.512 & & & 53.67 & 3.786 & & \\
\hline Secondary & 13 & 39.15 & 5.414 & & & 51.69 & 5.588 & & \\
\hline $\begin{array}{c}\text { Higher } \\
\text { secondary }\end{array}$ & 34 & 42.06 & 4.313 & & & 53.29 & 5.834 & & \\
\hline $\begin{array}{l}\text { Graduate/ Post } \\
\text { Graduate }\end{array}$ & 27 & 41.48 & 5.550 & & & 51.11 & 7.658 & & \\
\hline \multicolumn{10}{|l|}{ Occupation } \\
\hline Retired & 2 & 40.00 & 0.000 & \multirow{4}{*}{0.40} & \multirow{4}{*}{0.76} & 53.50 & 3.536 & \multirow{4}{*}{0.47} & \multirow{4}{*}{0.70} \\
\hline Business & 12 & 40.00 & 4.492 & & & 51.92 & 7.740 & & \\
\hline Salaried & 50 & 41.22 & 5.080 & & & 52.90 & 5.304 & & \\
\hline House maker & 16 & 42.00 & 5.465 & & & 50.81 & 8.416 & & \\
\hline \multicolumn{10}{|c|}{ Monthly Income (INR) } \\
\hline None & 19 & 41.42 & 5.263 & \multirow{3}{*}{4.32} & \multirow{3}{*}{0.017} & 51.16 & 7.776 & \multirow{3}{*}{0.68} & \multirow{3}{*}{0.51} \\
\hline$<15000$ & 26 & 39.00 & 4.345 & & & 53.38 & 5.721 & & \\
\hline $15000 \&$ above & 35 & 42.63 & 4.839 & & & 52.23 & 5.961 & & \\
\hline \multicolumn{10}{|c|}{ Period of caregiving } \\
\hline From 3 months & 19 & 43.26 & 6.261 & \multirow{4}{*}{1.67} & \multirow{4}{*}{0.18} & 49.16 & 7.733 & \multirow{4}{*}{2.45} & \multirow{4}{*}{0.07} \\
\hline From 6 months & 34 & 40.50 & 4.315 & & & 53.59 & 5.028 & & \\
\hline From 10 months & 18 & 40.06 & 4.331 & & & 53.67 & 5.029 & & \\
\hline $\begin{array}{l}\text { More than } 1 \\
\text { year }\end{array}$ & 09 & 41.44 & 5.053 & & & 51.78 & 8.288 & & \\
\hline Relation with pat & & & & & & & & & \\
\hline Spouse & 29 & 39.21 & 5.345 & & & 54.83 & 4.560 & & \\
\hline Parent & 06 & 41.83 & 2.927 & 255 & 006 & 55.17 & 5.037 & 465 & 0005 \\
\hline Child & 24 & 42.63 & 5.380 & 2.J & 0.002 & 51.71 & 6.649 & 4.03 & 0.005 \\
\hline Other & 21 & 42.00 & 3.701 & & & 48.86 & 6.901 & & \\
\hline
\end{tabular}

Table 4.Correlation between Compassion Satisfaction and Compassion Fatigue

$N=80$

\begin{tabular}{|c|c|c|}
\hline Variables between which Correlation is evaluated & r Value & P Value \\
\hline Compassion Satisfaction and Compassion Fatigue & -0.48 & $<0.0001$ \\
\hline
\end{tabular}

\section{Discussion}

In the present study, majority of caregivers $(41,51.2 \%)$ had average compassion satisfaction level while $39(48.8 \%)$ had a high level of compassion satisfaction. Similar findings were reported by Lynch SH et al. (2018) where majority of the participants $(82.2 \%)$ reported moderate compassion satisfaction. ${ }^{12}$

The mean of compassion satisfaction in the present study 
was 41.16 which ranged from average to high level. Mosher CE et al. (2017) identified five positive changes in caregivers while caring for patients with cancer. These changes are closer relationships with others, greater appreciation of life, clarifying life priorities, increased faith, and more empathy for others. ${ }^{13}$ When families care for their loved ones, not everything is a negative experience. It can have positive effects on mental processes and may improve their perception of life.

All the participants in the study had compassion satisfaction ranging from average to high level while none had low compassion satisfaction. In India, it is obvious that family members take prime responsibility to provide care and support to the sick people. Moreover, most of the caregivers were either spouse or children who are always expected to take care of their diseased spouse or parents. The cultural influence thus has a significant impact on the attitude of family members towards the sick.

In the case of level of compassion fatigue, in the present study majority of participants $(74,92.5 \%)$ had high compassion fatigue and only $6(7.5 \%)$ had moderate compassion fatigue. Similar findings were seen by Lynch $\mathrm{SH}$, et al. (2018) where majority of participants (71\%) reported high level of caregiver burden. $59.5 \%$ of participants reported moderate to low compassion fatigue while $50 \%$ of participants reported secondary traumatic stress. ${ }^{12}$

In contrast to the above findings, a hospital-based study done in Delhi by Lukhmana S et al. (2015) showed that majority of family caregivers $(56.5 \%)$ had no or minimal burden due to caregiving and $43.5 \%$ had caregiver burden of varying degrees ranging from mild to severe. ${ }^{11}$

The mean of compassion fatigue was 52.35 where maximum participants experienced high level of fatigue. High level of compassion fatigue found in most of the participants indicates the inability to cope with the patient's illness and poor quality of life among caregivers. Even though the satisfaction of care provided was average to high in this group, many times response to care and treatment determines their stress level. Chemotherapy is one of the major modalities of the treatment of cancer, but its outcome depends on the stages and type of patient's illness. Provision of supportive care and regular treatment does not always ensure improvement in patient's health. In this group, there were a considerable number of patients who were undergoing palliative chemotherapy which may alleviate the symptoms of patients but there is a lot of uncertainty involved. Some caregivers may perceive this as a futile effort because treatment may not always ensure patient's survival. All these factors may add stress and anxiety to the life of caregivers.

Simone MCH et al. (2019) found that female spouses had higher baseline levels of burden and fatigue caring for chemo-radiotherapy patients with lower levels of global HRQoL. ${ }^{14}$ In the present study compassion fatigue was significantly associated with the relationship of caregivers. Most of the caregivers in the study group were spouse or children of the patients.

The gender of caregivers was found to be not statistically significant with the level of compassion fatigue. These findings are consistent with that of Longacre and colleagues (2012) in their review of the psychological health of caregivers of patients with head and neck cancer. They did not find any consistency on the caregivers' risk on higher levels of burden in relation to the female gender. ${ }^{15}$

The level of compassion satisfaction or compassion fatigue is found to be not significantly associated with the period of caregiving. Nightingale and colleagues (2014) reported that there is an increase in burden during the course of chemotherapy and/ or radiotherapy, which remains high up to the end of treatment and there is no change in burden as per the period of caregiving. ${ }^{16}$ Badr and colleagues (2014) had similar findings of constant levels of burden, up to 6 weeks after initiating treatment (radiotherapy alone, and/ or in combination with prior surgery and/ or chemotherapy). ${ }^{17}$ Simone $\mathrm{MCH}$ et al. (2019) had contrast findings of an increase in burden 1 week after chemoradiotherapy and a decrease in baseline levels 3 months after chemo-radiotherapy. ${ }^{14}$

The study done on nurses by Borges and colleagues (2019) found that compassion satisfaction was higher than secondary traumatic stress in older participants as compared to their younger counterparts. Younger participants were found to have a lower level of compassion fatigue but a higher level of secondary traumatic stress. ${ }^{18} \mathrm{~A}$ similar study done by Kabunga and colleagues (2016) on psychotherapists found that those aged $25-34$ years (64.0\%) experienced a high level of compassion fatigue as compared to an older participants ${ }^{19}$, but in the present study, age was not found to be related to either compassion fatigue or satisfaction.

The occupation of caregivers was not associated with the level of compassion satisfaction or fatigue. Most of the caregivers were salaried. Some of the caregivers voiced their concern for not being able to adjust with their work timings and assumed the role of a caregiver as their nature of work is time-bound. Sometimes due to stiff timings of work, the caregiving process may get affected which can also cause frustration due to the unavailability of caregivers when patients need them the most. On the other hand, it is seen that caregivers utilise work hours as a break from the caregiver role. This gives them some sense of relief from patient care which can prove beneficial to alleviate their stress level. 


\section{Implications of Findings in Nursing}

Oncology nurses are uniquely positioned to play a vital role in recognising caretaker strain and intervening to break the cycle of unremitting physical and psychological burden. Caretakers should be assessed and reassessed over time by nursing persons for fatigue, sleep quality, health problems and self-care behaviours such as exercise, nutrition, recreational activities, rest and sleep. Health care professionals should include caregivers in the routine assessment and care planning of patients while they are in the hospital. Nursing interventions should be carried out to control and manage fatigue, depression and burden of patients as well as caretakers.

Nurse administrators can design counselling sessions, psychoeducation programmes, partner guided programmes, pain management training programmes, skill training programmes, and various structured education that will be beneficial for both the patient and the caretaker. This will enable the caretaker to support and guide their patients and improve the patient's quality of life.

\section{Conclusion and Recommendations}

Findings suggest that despite high caregiver compassion fatigue, family caregivers are able to provide care and find average to high levels of satisfaction in their role. Several personal attributes place a person at risk for developing compassion fatigue. Monthly income and relation with caregiver were two attributes found to be associated with caregiver compassion fatigue.

Caring for the sick and dying is both physically and emotionally demanding, making the caregivers more vulnerable to compassion fatigue or traumatic stress. If not addressed in its earliest stages, compassion fatigue can adversely change the caregiver's ability to provide compassionate care especially when the focus is shifting to home-based care.

In a hospital setting, the focus of treatment is always on the patient and little attention is paid to the needs of their caregivers who can also potentially get affected because of stress and traumatic experiences faced during the process of treatment. There is a lot of work found for the needs and satisfaction of the family of a critically ill person, but the needs of family caregivers of patients with cancer or such chronic illnesses are more unique. These needs should be studied further so as to include one or more relevant health measures for them in order to prevent potential physical and mental issues.

\section{Acknowledgement: None \\ Source of Funding: None \\ Conflict of Interest: None}

\section{References}

1. Coroner talk [Internet]. Secondary traumatic stress: getting through what you can't get over. 2015. Available from: https://coronertalk.com/secondary-traumaticstress-getting-through-what-you-cant-get-over

2. Lynch SH, Lobo ML. Compassion fatigue in family caregivers: a Wilsonian concept analysis. J Adv Nurs. 2012;68(9):2125-34. [PubMed] [Google Scholar]

3. Reinhard SC, Given B, Petlick NH, Bemis A. Supporting Family Caregivers in Providing Care. In: Hughes RG, editor. Patient Safety and Quality: An Evidence-Based Handbook for Nurses. Rockville (MD): Agency for Healthcare Research and Quality (US); 2008 Apr.

4. Gorman LM. The Psychosocial Impact of Cancer on the Individual, Family, and Society. Oncological Nursing Society; 2018. [Google Scholar]

5. Eldridge L. Compassion fatigue and Burnout in Cancer Caregivers. 2019 Nov.

6. Pashib M, Abbaspour S, Tadayyon H, Khalafi A. Quality of professional life among nurses of hospitals in Torbat Heydariyeh city in 2016. J Torbat Heyda Univ Med Sci. 2016;4:36-41. [Google Scholar]

7. Babaei S, Taleghani F, Kayvanara M. Compassionate behaviours of clinical nurses in Iran: an ethnographic study. Int Nurs Rev. 2016 Sep;63(3):388-94. [PubMed] [Google Scholar]

8. Burton LC, Newsom JT, Schulz R, Hirsch CH, German PS. Preventive health behaviors among spousal caregivers. Prev Med. 1997;26(2):162-9. [PubMed] [Google Scholar]

9. Levine $C$. Rough crossings: Family caregivers' odysseys through the health care system. New York: United Hospital Fund of New York; 1998.

10. Neal MB, Chapman NJ, Ingersoll-Dayton B, Emlen AC. Balancing work and caregiving for children, adults, and elders. Vol. 3. Sage Publications; 1993. [Google Scholar]

11. Lukhmana S, Bhasin SK, Chhabra P, Bhatia MS. Family caregivers' burden: A hospital based study in 2010 among cancer patients from Delhi. Indian J Cancer. Jan-Mar 2015;52(1):146-51.[PubMed] [Google Scholar]

12. Lynch SH, Shuster G, Lobo ML. The family caregiver experience - examining the positive and negative aspects of compassion satisfaction and compassion fatigue as caregiving outcomes. Aging Ment Health. 2018 Nov;22(11):1424-31. [PubMed] [Google Scholar]

13. Mosher CE, Adams RN, Helft PR, O'Neil BH, Shahda $S$, Rattray NA, Champion VL. Positive changes among patients with advanced colorectal cancer and their family caregivers: a qualitative analysis. Psychol Health. 2017;32(1):94-109. [PubMed] [Google Scholar]

14. Langenberg SM, van Herpen CM, van Opstal CC, Wymenga AN, van der Graaf WT, Prins JB. Caregivers' 
burden and fatigue during and after patients' treatment with concomitant chemoradiotherapy for locally advanced head and neck cancer: a prospective, observational pilot study. Support Care Cancer. 2019;27:4145-54. [PubMed] [Google Scholar]

15. Longacre ML, Ridge JA, Burtness BA, Galloway TJ, Fang CY. Psychological functioning of caregivers for head and neck cancer patients. Oral Oncol. 2012;48(1):1825. [PubMed] [Google Scholar]

16. Nightingale $\mathrm{CL}$, Lagorio L, Carnaby G. A prospective pilot study of psychosocial functioning in head and neck cancer patient-caregiver dyads. J Psychosoc Oncol. 2014;32(5):477-92. [PubMed] [Google Scholar]

17. Badr H, Gupta V, Sikora A, Posner M. Psychological distress in patients and caregivers over the course of radiotherapy for head and neck cancer. Oral Oncol. 2014;50(10):1005-11. [PubMed] [Google Scholar]

18. das Neves Borges EM, da Silva Fonseca $\mathrm{Cl}$, Baptista PC, Queirós CM, Baldonedo-Mosteiro M, MosteiroDiaz MP. Compassion fatigue among nurses working on an adult emergency and urgent care unit. Rev Lat Am Enfermagem. 2019 Oct 7;27:e3175. [PubMed] [Google Scholar]

19. Kabunga A, Mbugua S, Makori G. Compassion Fatigue: A Study of Psychotherapists' Demographics in Northern Uganda. Int J Acad Res Psychol. 2016;3(1):49-59. [Google Scholar] 